\title{
An Analysis of the Production Efficiency of Large Coal Enterprises in China and its Enlightenment to the Enterprises in Mongolia
}

\author{
Rigaqiqige $\mathrm{Wu}^{1, \mathrm{a}}$, Zhanxin $\mathrm{Ma}^{2, \mathrm{~b}^{*}}$ and $\mathrm{Min} \mathrm{Nuo}^{3, \mathrm{c}}$ \\ ${ }^{1}$ School of Economics and Management, Inner Mongolia University, Hohhot 010021 \\ ${ }^{2}$ School of Economics and Management, Inner Mongolia University, Hohhot 010021 \\ ${ }^{3}$ School of Economics and Management, Inner Mongolia University, Hohhot 010021 \\ aurgaa93@163.com, bem_mazhanxin@imu.edu.cn, chi_nomiko@yahoo.com
}

Keywords: Data envelopment analysis; Coal enterprise; Enterprise efficiency; Evaluation index; Comprehensive efficiency; Technical efficiency

Abstract. Because of the advantage of geographical location between China and Mongolia, and the advantage of industrial structure and exchange space, China and Mongolia's trade development prospects are wide. Therefore, this paper chooses the data of China's 15 major coal listed companies from 2009 to 2014 to study, in order to enhance the efficiency of Mongolian enterprises and to promote the Sino Mongolian cooperation and exchange. The main work of this paper is to introduce the background and significance of the topic, to analysis the energy efficiency in the DEA, to establish the evaluation index system and analysis of the efficiency of China's coal enterprises.

\section{Introduction}

Investment in China's coal industry and in Mongolia coal industry accounts for higher rates due to China and Mongolia close geographical location. Mongolia is a potential energy country but it is a funds shortage economy developed countries, while China has advanced technology, professional personnel and adequate investment funds. Obviously, the two countries have great differences, which make China and Mongolia have complementary economic advantages. Therefore, the analysis of production efficiency of large coal enterprises in China has become an important research object in the relevant research fields. This paper uses the data envelopment analysis method to analyze the status and efficiency of coal enterprises, and then explains the development structure of China's coal enterprises and the policy of the coal enterprises in Mongolia. Therefore, how to improve the energy efficiency through its business restructuring becomes a worthy discussion. Recently, many domestic scholars use the DEA method to study deeply the efficiency of the coal industry. In the paper [1] 40 coal enterprises panel data was taken as the researching samples, DEA and SFA methods were united to evaluate efficiency of the coal enterprises from 2004 to 2006 and the relativity and coincidence was tested. By using the $C^{2} R$ model of DEA, the paper [2] analyzed the operating performance of Chinese 17 coal enterprises listed companies based on the data from their recent 2 years' annual reports. By using generalized DEA methods, the paper [3] analyzes Chinese coal listed companies from 2000 to 2008 panel data. The paper [4] introduces the difference and relation between the generalized reference set DEA method and the traditional DEA method. In the paper [5], a non-parametric method based on the overall performance of the decision making unit is constructed, and the corresponding mathematical model is constructed, and the economic benefit of industrial enterprises in Western China is analyzed by using the method.

\section{The Model for Evaluating the Production Efficiency of Large Coal Enterprises}

According to panel data, the following generalized DEA model ${ }^{[6]}$ is given. It is assumed that the input and output conditions of a n similar decision making unit can be reflected by $\mathrm{M}$ input and s output indicators, and the input and output indexes of the $\mathrm{P}$ decision making units in the first $\mathrm{k}$ time periods are measured $\left(\boldsymbol{x}_{p}^{(k)}, \boldsymbol{y}_{p}^{(k)}\right)$ and $\boldsymbol{x}_{p}^{(k)}=\left(x_{1 p}^{(k)}, x_{2 p}^{(k)}, \cdots, x_{m p}^{(k)}\right)^{\mathrm{T}}, \boldsymbol{y}_{p}^{(k)}=\left(y_{1 p}^{(k)}, y_{2 p}^{(k)}, \cdots, y_{s p}^{(k)}\right)^{\mathrm{T}}$, 
$\boldsymbol{x}_{p}^{(k)}>\mathbf{0}, \boldsymbol{y}_{p}^{(k)}>\mathbf{0}, \quad p=1,2, \cdots, n, k=1,2, \cdots, L$ If the sample unit is set to the first J0 time period (based on the time period), the value of the input and output index is $\boldsymbol{x}_{j}^{(0)}=\left(x_{1 j}^{(0)}, x_{2 j}^{(0)}, \cdots, x_{m j}^{(0)}\right)^{\mathrm{T}}>0$, $\boldsymbol{y}_{j}^{(0)}=\left(y_{1 j}^{(0)}, y_{2 j}^{(0)}, \cdots, y_{s j}^{(0)}\right)^{\mathrm{T}}>0$, The generalized DEA model based on panel data ${ }^{[7]}$ is given:

$$
\text { (D-panel) }\left\{\begin{array}{l}
\min \theta-\varepsilon\left(\hat{\boldsymbol{e}}^{T} \boldsymbol{s}^{-}+\boldsymbol{e}^{T} \boldsymbol{s}^{+}\right), \\
\text {s.t. } \sum_{j=1}^{n^{(0)}} \lambda_{j} \boldsymbol{x}_{j}^{(0)}+\boldsymbol{s}^{-}=\theta \boldsymbol{x}_{p}^{(k)}, \\
\quad \sum_{j=1}^{n^{(0)}} \lambda_{j} \boldsymbol{y}_{j}^{(0)}-\boldsymbol{s}^{+}=\boldsymbol{y}_{p}^{(k)}, \\
\delta \sum_{j=1}^{n^{(0)}} \lambda_{j}=\delta \\
\lambda_{j} \geqq 0, j=1,2, \cdots, n^{(0)} \\
\mathbf{s}^{+} \geq \mathbf{0}, \boldsymbol{s}^{-} \geq \mathbf{0} .
\end{array}\right.
$$

\section{The production efficiency of coal enterprises in China}

This paper mainly adopts CCR model returns to scale invariant measure efficiency value and BCC model returns to scale changes measured efficiency value method to carry on the related research and analysis, to understand the actual situation of the enterprise efficiency of coal enterprises in China.

Establishment of Data Source and Evaluation Index. According to the research needs of establishing index system ${ }^{[8]}$, considering the principle of index selection and the actual situation, we set up the evaluation index system of coal in China and Mongolia. The evaluation index system includes two types of input and output indicators, the main body of the input indicators reflect the enterprise's human resources investment, enterprise assets change and reflect the value of production and business activities. The main content of the output index is to reflect the enterprise sales and service quality and measure the performance of enterprise production and operation.

In order to study the production efficiency of coal enterprises in China more completely and more systematically, the main factors that affect the efficiency of coal enterprises and the solutions are analyzed. This paper collects the data from 15 coal listing Corporation in 2009 to 2014 in China. Among them, the evaluation comparison of the sample for the 2009 to 2014 of the interface data, the evaluation unit for 2009-2014 years of China's coal enterprise data.

An Empirical Analysis on the Efficiency of Large Coal Enterprises in China. In this paper, we collect the 2009-2014 China 15 large-scale coal enterprise efficiency index data ${ }^{[9]}$, and the data using the data envelopment analysis (DEA method, the DEA has two commonly used models: CCR model and BCC model, two model analysis - efficiency of enterprise value. As shown in table 1.

Analysis on the comprehensive efficiency of energy utilization in 2009 2014

Table 1 Comprehensive efficiency of coal enterprises in China

\begin{tabular}{lrrrrrr}
\hline Enterprise & 2009 & 2010 & 2011 & 2012 & 2013 & 2014 \\
\hline SH & 0.9992 & 0.9992 & 0.9967 & 0.9901 & 1.1434 & 0.9735 \\
JZ & 1.0037 & 1.0051 & 1.0055 & 1.0070 & 1.1936 & 0.9465 \\
CG & 1.0879 & 1.0890 & 1.0875 & 1.0793 & 1.0218 & 0.7949 \\
XSME & 1.0076 & 1.0113 & 1.0148 & 1.0131 & 1.2303 & 1.0000 \\
ZZMP & 1.0917 & 1.0959 & 1.1211 & 1.0407 & 0.9958 & 0.9920 \\
LHKC & 1.0511 & 1.0457 & 1.0396 & 1.0308 & 1.0144 & 1.0000 \\
YZMI & 1.0160 & 1.0266 & 1.0296 & 1.0082 & 1.0052 & 1.0000 \\
PJ & 1.0080 & 1.0083 & 1.0074 & 1.0061 & 1.0044 & 1.0000
\end{tabular}




\begin{tabular}{lllllll} 
SHE & 1.0186 & 1.0211 & 1.0223 & 1.0213 & 1.0249 & 0.9979 \\
AS & 1.1178 & 1.1241 & 1.1184 & 1.1243 & 1.1303 & 0.9996 \\
AY & 1.1444 & 1.1397 & 1.1417 & 0.9988 & 1.0048 & 0.9944 \\
CYXE & 1.0005 & 1.0024 & 1.0289 & 1.0841 & 0.9967 & 0.9972 \\
RM & 1.2057 & 1.2062 & 1.2060 & 1.2056 & 1.2061 & 1.0000 \\
HYCE & 1.0043 & 1.0045 & 1.0047 & 1.0027 & 1.0019 & 0.9970 \\
KLE & 1.0907 & 1.1043 & 1.1066 & 1.1059 & 1.1047 & 0.9985 \\
\hline
\end{tabular}

From the table 1 can be seen, China's large-scale coal enterprises in the energy utilization of the average comprehensive efficiency is basically located between 0.95 1.08, showing a downward trend overall.

Analysis on technical efficiency of energy utilization in 2009 2014

First of all, in 2009 China's coal enterprises data as the reference system, the application of DEA model can be 2009 2014 years, China's large-scale coal enterprises technical efficiency analysis value as shown in table 2.

Table 2 Technical efficiency of coal enterprises in China

\begin{tabular}{|c|c|c|c|c|c|c|}
\hline Enterprise & 2009 & 2010 & 2011 & 2012 & 2013 & 2014 \\
\hline $\mathrm{SH}$ & 1.0008 & 0.9992 & 0.9967 & 0.9901 & 1.0000 & 0.9744 \\
\hline $\mathrm{JZ}$ & 1.0037 & 1.0051 & 1.0055 & 1.0070 & 1.0000 & 0.9712 \\
\hline CG & 1.0886 & 1.0894 & 1.0875 & 1.0799 & 1.0355 & 0.8046 \\
\hline XSME & 1.0076 & 1.0113 & 1.0158 & 1.0140 & 1.0000 & 1.0000 \\
\hline ZZMP & 1.0917 & 1.0959 & 1.1211 & 1.0407 & 0.9958 & 0.9920 \\
\hline LHKC & 1.0511 & 1.0457 & 1.0396 & 1.0308 & 1.0144 & 1.0000 \\
\hline YZMI & 1.0160 & 1.0266 & 1.0296 & 1.0082 & 1.0052 & 1.0000 \\
\hline PJ & 1.0206 & 1.0192 & 1.0134 & 1.0101 & 1.0107 & 1.0000 \\
\hline SHE & 1.0207 & 1.0211 & 1.0223 & 1.0213 & 1.0249 & 0.9979 \\
\hline AS & 1.1198 & 1.1260 & 1.1201 & 1.1257 & 1.1318 & 0.9996 \\
\hline AY & 1.1472 & 1.1423 & 1.1435 & 1.0107 & 1.0112 & 0.9944 \\
\hline CYXE & 1.0005 & 1.0024 & 1.0289 & 1.0841 & 0.9967 & 0.9972 \\
\hline $\mathrm{RM}$ & 1.2069 & 1.2072 & 1.2070 & 1.2064 & 1.2067 & 1.0000 \\
\hline HYCE & 1.0146 & 1.0132 & 1.0120 & 1.0093 & 1.0096 & 0.9970 \\
\hline KLE & 1.0907 & 1.1043 & 1.1066 & 1.1059 & 1.1047 & 0.9989 \\
\hline
\end{tabular}

From the table 2 can get 2009 2014 China 15 large coal enterprises of the technical efficiency value with the comprehensive efficiency value is slightly similar, there is a downward trend.

In short, from the above analysis see China's large-scale coal enterprises efficiency generally have downward trend, which showed that although the efficiency of China's coal enterprise value is equal to or greater than 1, but annual increasing ratio decreased so the overall ratio decreased, did not achieve the effective area of DEA model and need to further improve.

\section{Conclusions}

Coal is the main source of energy in China, is the upper reaches of the industry, but also China's energy which can not be replaced. China's coal enterprises is faced with a stronger development competition and the production efficiency of coal enterprises further improve can contribute to the development of energy between China and Mongolia. Through this article to understand the situation of China's coal enterprises in recent years, and then to illustrate the situation of China's coal enterprises in Mongolia coal mining enterprises. Here are two inspirations for the enterprises in Mongolia: 
From the level of enterprises policy : It is hope that Mongolia should first understand the present situation of coal enterprise in Mongolia, companies are now developing trend, enterprise management based on absorbing experiences and suggestions on China's coal enterprise management experts, to the most suitable method of Mongolian enterprises transfer to the enterprise managers. Coal enterprises to apply the basic characteristics of the method of circular economy, construction technology carrier, rational use of resources and energy, improve the production and development of circular economy. The implementation of the development strategy, rational and orderly use of coal resources, strengthen management and resource use efficiency, improve enterprise management system, the establishment of modern enterprise management policy.

From the level of government policy: The government of Mongolia should study from China's coal enterprises, the present situation, development trend, business management and other aspects of the information, and understand the enterprise structure and pattern of Mongolian coal enterprises. It is essential that the government should take effective policies to support and encourage the development trend of coal enterprises and take appropriate policy measures and technical. They ought to improve the coal power management level, prevent excessive decentralization of coal right supervision, increase the positive interaction between enterprises, and deepen the exchange of professional and technical research.

\section{Acknowledgment}

This work is supported by National Natural Science Foundation of China (71261017, 70961005), Natural Science Foundation of Inner Mongolia (2016MS0705) and Inner Mongolia Prairie Excellence Specialist Project (12000-12102012).

\section{References}

[1] P. Yao and J. G. Liang: Journal of China Coal Society, Vol. 33 (2008), p.1

[2] Y. K. Peng and W. Zhang: Economic Mathematics, Vol. 27 (2010), p. 1

[3] Z. X. Ma: Journal of Systems Engineering and Electronics, Vol. 33 (2012), p.709-714.

[5] Z. X. Ma and R. YI: Control and decision, Vol. 27 (2012), p.199-204.

[6] Z. X. Ma and D. Wen: Research on the Economic practice -based on the Panel Data of Chinese Regions [C]. Proceedings of 2010 International Conference on Regional Management Sciences and Engineering, Vol. 1 (2010), p.369-373.

[7] T. T. Rao and T. Lv: China Mining Industry, Vol. 18 (2009), p.27-31

[8] Z. X. Ma: Data envelopment analysis (DEA) and Its Application Cases [M].Beijing: Science Press, 2013: 188-202.

[9] R. S. Fare, M. N. Grosskopf and Z. Zhang: American Economic Review, Vol. 84 (1994), p.66-83 